\title{
Laser-Driven Proton Acceleration Research and Development
}

\author{
Alexander S. Pirozhkov, Hiroyuki Daido, \\ Mamiko Nishiuchi and Koichi Ogura \\ Advanced Photon Research Center and Photo-Medical Research Center, \\ Japan Atomic Energy Agency \\ Japan
}

\section{Introduction}

Up to now the acceleration of charged particles in most cases is based on the radio-frequency based technology. Another approach is to employ ultrahigh collective fields of plasmas produced by high-power lasers. Using various schemes, these plasma fields can be used to accelerate electrons, protons, and heavier ions. Laser-driven ion beams exhibit unique properties, among which are short duration, small source size, large number of particles, low emittance, etc. The laser-driven acceleration is inherently a very compact process, because the acceleration typically takes place within a micrometer spatial and picosecond time scales; the acceleration field can exceed $\mathrm{TV} / \mathrm{m}$, which allows achieving multi-MeV/nucleon ion energies. For the detailed reviews, see (Borghesi et al. 2006; Mourou et al. 2006) and references therein. The peculiar properties of the laser-driven proton beam, namely short duration, low emittance, and large particle number have been used in the proton imaging, which allows measurement of transient field distribution in plasma experiments (Borghesi et al. 2001); the broad proton energy spectrum allows multi-frame time-resolved studies in single shot. A compact laserbased laboratory setup has been used for the proof-of-principle radiological experiment (Yogo et al. 2009), which can be applicable in the biological, medical, and space research (Murakami et al. 2009). There are many other attractive potential applications of the laser-driven ion beams, among which the hadron therapy (Bulanov et al. 2002; Bulanov \& Khoroshkov 2002), fast ignition (Roth et al. 2001), injectors into conventional accelerators (Krushelnick et al. 2000; Cowan et al. 2004), material processing, isotope production (Nemoto et al. 2001; Fritzler et al. 2003), pion production (Bychenkov et al. 2001), pump-probe experiments using simultaneous production of proton beam and THz radiation (Sagisaka et al. 2008), x-rays (Orimo et al. 2007), electrons ( $\mathrm{Li}$ et al. 2006), and so on.

For many applications, the parameters of the presently available laser-driven ion beams need to be improved. In particular, it is necessary to increase the maximum ion energy, simultaneously achieving high conversion efficiency. At present, this is an active area of research. Up to now a substantial part of results has been obtained with relatively largescale, single-shot picosecond and sub-picosecond laser systems (Hatchett et al. 2000; Snavely et al. 2000; Fuchs et al. 2006; Robson et al. 2007; Henig et al. 2009). However, for many applications a compact, repetitive ion source is necessary. For such applications, it is

Source: Advances in Solid-State Lasers: Development and Applications, Book edited by: Mikhail Grishin, ISBN 978-953-7619-80-0, pp. 630, February 2010, INTECH, Croatia, downloaded from SCIYO.COM 
attractive to use high-power femtosecond lasers, which have smaller pulse energies at the same power levels, and therefore can provide higher repetition rates. In this Chapter we present the results of proton acceleration and plasma diagnostic experiments (Pirozhkov et al. 2009c) conducted with a repetitive femtosecond J-KAREN laser at the Advanced Photon Research Center, Japan Atomic Energy Agency. In Sections 2 and 3 we describe the laser parameters and the results of the experiments and discuss the influence of several parameters on the maximum proton energy; we show the strong influence of the laser contrast on the proton acceleration process. In Section 4 we analyze the results of the ontarget laser contrast measurement, which has been performed at full laser power using the properties of radiation reflected from the target. In Section 5 we describe the laser-driven proton beam manipulation using permanent magnet quadrupoles. In Section 6 we describe the radioactivation experiments using multi-MeV laser-driven proton source.

\section{Lasers for proton acceleration: present status and future prospects}

\subsection{High-power picosecond and femtosecond lasers}

Up to now, the highest proton energies, the largest proton numbers and conversion efficiencies have been obtained using high-energy ps and sub-ps lasers. The proton energies close to $60 \mathrm{MeV}$ (Hatchett et al. 2000; Snavely et al. 2000; Robson et al. 2007) have been achieved using petawatt lasers based on the Chirped Pulse Amplification (CPA) technology (Strickland \& Mourou 1985). In these experiments, thin foil targets were irradiated by the focused laser pulses with intensities exceeding $1020 \mathrm{~W} / \mathrm{cm}^{2}$; regardless of the target material, the accelerated ions were predominantly protons originating from the water or hydrocarbon surface contamination. If the contamination was removed e.g. by joule or laser heating, heavier ions had been accelerated (Hegelich et al. 2002; McKenna et al. 2004). The acceleration has been attributed to the process known as Target Normal Sheath Acceleration (TNSA) (Hatchett et al. 2000; Mora 2003).

The experiments in which multi- $10 \mathrm{MeV} /$ nucleon protons and ions were accelerated within very short acceleration distances have caused great interest to the field of laser-driven ion acceleration. One of the attractive directions of research is miniaturization of the accelerator employing compact, relatively high-repetition rate CPA lasers with even shorter (femtosecond) pulse durations; the compactness and higher repetition rate can be achieved in this case because of the smaller pulse energy required to provide similar peak power and intensity. However, at present the achievable proton energies in this case are lower. Despite this, a number of application and proof-of-principle experiments have been performed with the ion and proton beams driven by compact femtosecond lasers. Ion energies up to 10-20 $\mathrm{MeV} /$ nucleon (Fukuda et al. 2009) and the laser-to-proton beam conversion efficiencies up to $3 \%$ (proton energy $>0.8 \mathrm{MeV}$ ) (Nishiuchi et al. 2008) have been demonstrated.

\subsection{J-KAREN laser}

The experiments described in this Chapter (Pirozhkov et al. 2009c) have been conducted using hybrid OPCPA/Ti:Sapphire J-KAREN laser (Kiriyama et al. 2008; Kiriyama et al. 2009); here OPCPA stands for the Optical Parametric Chirped Pulse Amplification. The laser consists of a CPA oscillator with high pulse energy, which facilitates achieving higher contrast, saturable absorber, stretcher, two- or three-stage OPCPA based on type I BBO crystals, two 4-pass Ti:Sapphire amplifiers, and vacuum compressor. The cryogenic cooling of the final amplifier (down to $100 \mathrm{~K}$ ) removes thermal lensing, which allows $10 \mathrm{~Hz}$ 
operation with high laser beam quality. The saturable absorber efficiently reduces the Amplified Spontaneous Emission (ASE) after the CPA oscillator, which is crucial for the solid target irradiation experiments, including the ion acceleration (see Sections 3 and 4). The laser provides $\sim 30 \mathrm{fs}, \sim 1 \mathrm{~J}$ pulses at the wavelength of $\approx 820 \mathrm{~nm}$ with the nanosecond contrast higher than $10^{10}$. Employing an $\mathrm{f} / 3$ Off-Axis Parabola (OAP) mirror, the pulses are focused down to a 3-4 $\mu \mathrm{m}$ spot (Full Width at Half Maximum, FWHM). The short pulse duration and small focal spot allow achieving the peak irradiance of up to $1020 \mathrm{~W} / \mathrm{cm}^{2}$.

The temporal pulse shape on the femtosecond time scale (Fig. 1) was measured with the home-built Transient Grating Frequency-Resolved Optical Gating (TG FROG) system (Pirozhkov et al. 2008). The measured FWHM and effective widths of the pulses are $\tau_{F W H M}=$ $28 \mathrm{fs}, \tau_{\text {eff }}=35 \mathrm{fs}$ without and $\tau_{F W H M}=35 \mathrm{fs}, \tau_{\text {eff }}=47 \mathrm{fs}$ with the saturable absorber. (The effective width is the ratio of the pulse energy to the peak power.) The pulse duration with the saturable absorber is somewhat larger, because the saturable absorber introduces some high-order dispersion into the spectral phase, which cannot be compensated by the compressor. The power shown in Fig. 1 is calculated from the FROG data using the measured on-target pulse energies. The on-target energies without/with the saturable absorber are $E_{L}=880 \pm 20 \mathrm{~mJ}$ and $720 \pm 20 \mathrm{~mJ}$, respectively, which corresponds to the peak powers of $P_{0}=E_{L} / \tau_{\text {eff }}=25 \mathrm{TW}$ and $15 \mathrm{TW}$.

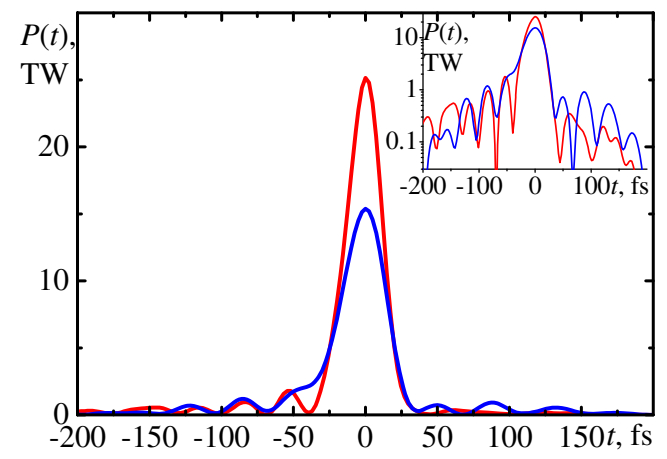

Fig. 1. Femtosecond pulse shape of J-KAREN laser measured with the Transient Grating Frequency-Resolved Optical Gating (TG FROG), the dispersion of the window and air has been subtracted. The red line corresponds to the case without the saturable absorber, the FWHM pulse duration $\tau_{F W H M}=28 \mathrm{fs}$, effective pulse duration $\tau_{\text {eff }}=35 \mathrm{fs}$ (FROG error $=0.008$, $N=128$ ), on-target energy $E_{L}=880 \mathrm{~mJ}$, peak power $P_{0}=25 \mathrm{TW}$. The blue line corresponds to the case with the saturable absorber, $\tau_{F W H M}=35 \mathrm{fs}, \tau_{\text {eff }}=47 \mathrm{fs}$ (FROG error $=0.002, N=256$ ), $E_{L}=720 \mathrm{~mJ}, P_{0}=15 \mathrm{TW}$. Inset, the same data in the log scale.

The intensity distribution of the laser pulses focused by the $f / 3$ OAP was measured by a microscope objective at full laser power operation; the pulses were attenuated using reflection from wedges and with neutral-density filters. Without the saturable absorber, the focal spot has an elliptical shape with side lobes [Fig. 2 (a)]. The major and minor axes of the ellipse have the FWHM sizes of $5.7 \pm 0.7 \mu \mathrm{m}$ and $2.28 \pm 0.11 \mu \mathrm{m}$, with the effective radius of $r_{\text {eff }}$ $=2.82 \pm 0.10 \mu \mathrm{m}$ (the errors are standard deviations of shot-to-shot fluctuations). With the saturable absorber, the shape of the focal spot is nearly circular [Fig. 2 (b)], with the FWHM of $3.3 \pm 0.3 \mu \mathrm{m}$ and $r_{e f f}=2.73 \pm 0.12 \mu \mathrm{m}$. The derived peak intensity is $I_{0}=P_{0} /\left(\pi r_{e f f}{ }^{2}\right)=1.0 \times 10^{20}$ $\mathrm{W} / \mathrm{cm}^{2}$ without and $0.7 \times 10^{20} \mathrm{~W} / \mathrm{cm}^{2}$ with the saturable absorber. 

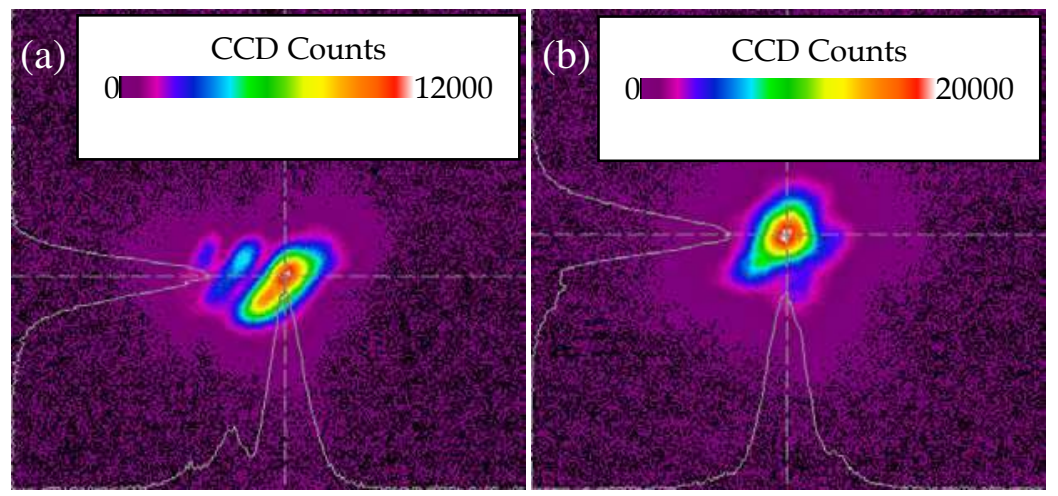

Fig. 2. Focal spot of J-KAREN laser focused with the $f / 3$ off-axis parabola. The spot is measured with a microscope objective at full power mode, the laser beam is attenuated by wedges and filters. (a) The case without the saturable absorber, the spot size FWHM = 5.7 $\mu \mathrm{m} \times 2.3 \mu \mathrm{m}$ (major and minor axes of the fitted ellipse), effective radius $r_{e f f}=2.8 \mu \mathrm{m}$, derived peak irradiance $I_{0}=1.0 \times 10^{20} \mathrm{~W} / \mathrm{cm}^{2}$. (b) The case with the saturable absorber, $\mathrm{FWHM}=3.3 \mu \mathrm{m}$ (nearly circular), $r_{\text {eff }}=2.7 \mu \mathrm{m}, I_{0}=0.7 \times 10^{20} \mathrm{~W} / \mathrm{cm}^{2}$.

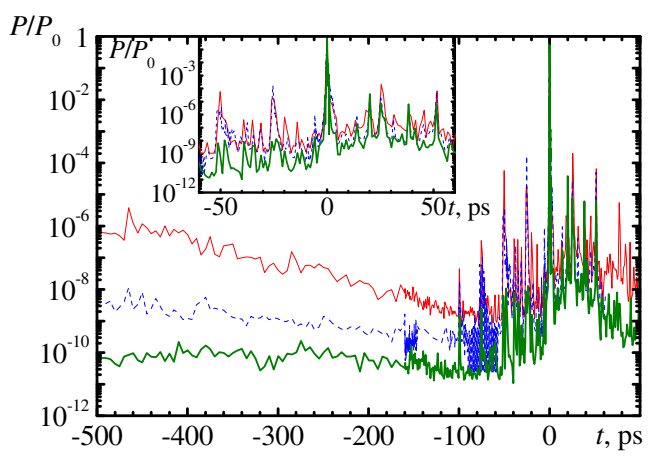

Fig. 3. Sub-nanosecond and picosecond contrast of J-KAREN laser in the three operation modes measured with the 3rd order cross-correlator: the thin red line is for the case of CPA oscillator, 3-stage OPCPA, and two multi-pass amplifiers (no saturable absorber). The blue dashed line is for the similar case but with the saturable absorber installed after the CPA oscillator. The thick green line is the same as the blue dashed line, but 2-stage (nonsaturated) OPCPA is used. The actual nanosecond contrast is $\sim 2-3$ times higher than shown in the figure due to the insufficient temporal resolution of the cross-correlator ( $120 \mathrm{fs})$; the estimated actual contrasts for the three cases are $\sim 5 \times 10^{6}, \sim 5 \times 10^{8}$, and $\sim 5 \times 10^{10}$. The inset shows the same data in more details within the time range of \pm 60 ps.

The contrast in different operation modes has been measured with the high-dynamic range 3-rd order cross-correlator (Fig. 3). The saturable absorber improves the contrast by a factor of 100. A similar improvement has been achieved by non-saturated OPCPA operation (two OPCPA stages instead of three) (Kiriyama et al. 2008). 


\section{Proton acceleration experiments with multi-10-TW J-KAREN laser}

\subsection{Experimental setup}

A typical schematic layout of the experiments is shown in Fig. 4. The OAP focused ppolarized laser pulses onto a tape or ribbon targets at the incidence angle of $45^{\circ}$. The tape target (Nayuki et al. 2003) supplied fresh surface for each shot, which allowed taking advantage of the high-repetition rate laser operation. The tapes were made from polyimide with the thicknesses of $7.5 \mu \mathrm{m}$ and $12.5 \mu \mathrm{m}$. The ribbon targets were made from metal ( $\mathrm{Al}$, $\mathrm{Au}, \mathrm{Pt}, \mathrm{Pd}$, etc.) with the thicknesses down to $200 \mathrm{~nm}$.

(a)
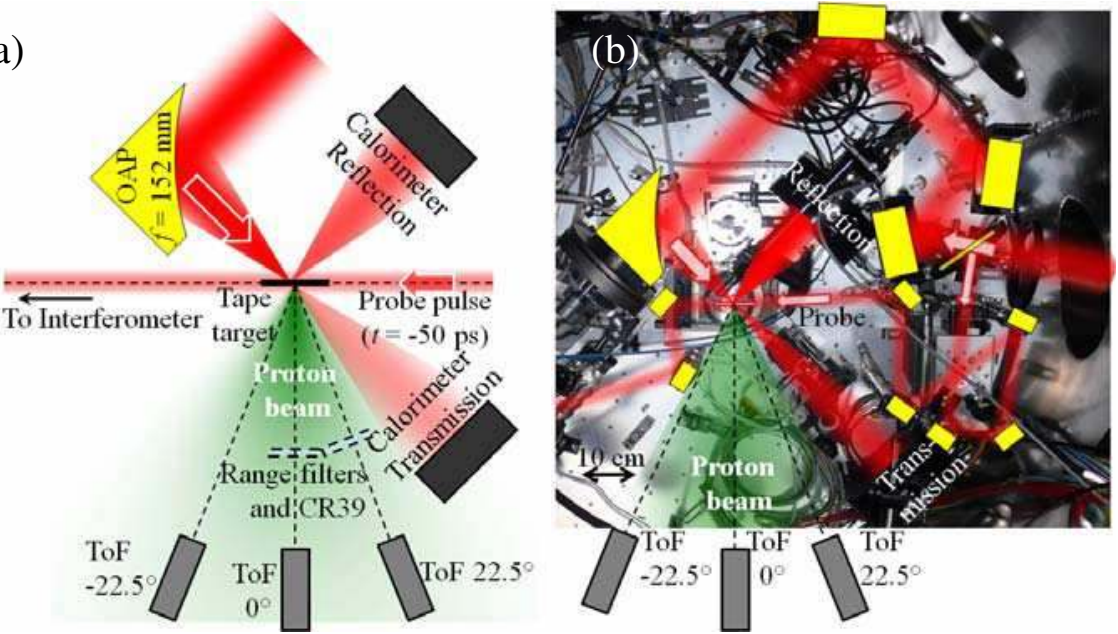

Fig. 4. Experimental setup. The p-polarized multi-10 TW laser pulses are focused by the $f / 3$ off-axis parabola (OAP) to the irradiances up to $10^{20} \mathrm{~W} / \mathrm{cm}^{2}$, the incidence angle on the target is $45^{\circ}$. The target can be a polyimide tape with the thickness of $7.5 \mu \mathrm{m}$ or $12.5 \mu \mathrm{m}$ as well as $\mathrm{Al}, \mathrm{Au}, \mathrm{Pd}$, or Pt ribbon with the thickness from few $\mu \mathrm{m}$ down to $200 \mathrm{~nm}$. The constantly moving tape targets allow the repetitive proton acceleration at $1 \mathrm{~Hz}$. The protons originating from the surface contamination are accelerated at the rear side of the target, predominantly perpendicular to the target surface. The protons are detected with several instruments, including the absolutely calibrated Time-of-Flight (ToF) spectrometers at $0^{\circ}$ and $\pm 22.5^{\circ}$ from the target normal (proton energy spectrum), CR-39 nuclear track detectors with the range filters (proton beam foot-print), and Thomson parabola with CR-39 detector (energy spectra of protons and other ions) (not shown). The laser-plasma interaction is studied with the interferometry and measurements of reflectivity and transmission. (a) A schematic layout. (b) A photo of the target chamber from the top with the superposed laser beams, mirrors, calorimeters, proton beam direction, and directions of observation with the Time-of-Flight spectrometers.

The protons were detected by the Time-of-Flight (ToF) spectrometers, CR-39 nuclear track detectors, and Thomson parabola. The ToF spectrometers (Nakamura et al. 2006; Yogo et al. 2007) were installed at the target normal direction and $\pm 22.5^{\circ}$ from it. In order to select the proton signal and reduce noise, the ToF spectrometers contained sweeping magnets removing all but the most energetic electrons, $\mathrm{Al}$ filters blocking laser and other light, and 
relatively thin plastic scintillator and the bent light guide that prevented the transmitted $x$ rays to enter the photomultiplier tube. The ToF spectrometers were absolutely calibrated with the conventional accelerator. The ToF spectrometers provide the proton spectrum immediately after the shot. This together with the constantly moving tape target allowed 1 $\mathrm{Hz}$ shooting, which has been used for quick optimization of the proton acceleration conditions. The CR-39 detectors with the range filters were used for the angular distribution and emittance measurements. Thomson parabola ion analyzer was used to check the contribution of other ion species.

To understand the laser-plasma interaction details, we used several plasma diagnostics. The probe beam split by a pellicle from the main pulse was used for shadowgraphy at $820 \mathrm{~nm}$ and interferometry at 820 and $410 \mathrm{~nm}(2 \omega)$ (Sagisaka et al. 2004; Sagisaka et al. 2006). To measure the laser energy reflected from and transmitted through the target, we used invacuum calorimeters. The calorimeter measuring the transmitted energy was used to measure the on-target laser pulse energy, when the target situated on a motorized 3-axis stage was moved out of the beam. Simultaneously, the third calorimeter measured leakage through one of the dielectric mirrors. After such cross-calibration, the on-target energy in each shot was derived from the dielectric mirror leakage, which allowed obtaining specular reflectivity and transmission.

\subsection{Results of proton acceleration}

We used a broad range of laser and target parameters to study the laser-driven acceleration properties and dependences on parameters. In order to achieve the maximum proton energies, a repetitive operation was employed to optimize the laser contrast, target position, pulse duration, etc.

The dependence of the maximum proton energy on the effective pulse duration is shown in Fig. 5. The pulse duration was varied by moving a grating in the compressor. The laser pulse shape was measured using the TG FROG (Fig. 1) (Pirozhkov et al. 2008). The spectrum and spectral phase measured with the TG FROG at some grating position allow calculating the shape of the laser pulse at any other grating position with high accuracy, as it was checked by direct comparison of the measured and calculated pulses. The effective pulse duration in Fig. 5 is therefore calculated from the TG FROG data obtained with the shortest pulse. The dependence of the maximum proton energy on the pulse duration is rather smooth, with the maximum at somewhat elongated pulse. This can be understood using the model of electrostatic acceleration of protons at the rear side of the target (Mora 2003; Fuchs et al. 2006) with the additional limit that the acceleration distance equals the sheath diameter (Robson et al. 2007). The dependence of the proton energy on the pulse duration obtained from this model (the dashed curve in Fig. 5) agrees well with the measurements.

The femtosecond pulses typically have a complicated structure in time. In particular, they have several kinds of preceding light, such as the ASE, prepulses, and picosecond pedestal. The preceding light can damage the target and create the preformed plasma well before the main pulse. To understand the influence of the preformed plasma on the proton acceleration, we employed the time-resolved interferometry using the femtosecond probe pulse (Sagisaka et al. 2004; Sagisaka et al. 2006). Fig. 6 shows the results of interferometry taken at 50 ps before the main pulse arrival. The ion spectra at the target normal direction recorded simultaneously with the interferograms shown in Fig. 6 are shown in Fig. 7. In the case of a relatively low contrast $\left(\sim 5 \times 10^{6}\right)$, the preplasma with the size of few hundred $\mu \mathrm{m}$ 
was formed [Fig. 6 (a)], and the proton energy was $2.3 \mathrm{MeV}$. On the other hand, when the high contrast mode was used $\left(\sim 5 \times 10^{10}\right)$, the preplasma was not detectable [Fig. 6 (c)], which means it was smaller than $\sim 20-30 \mu \mathrm{m}$. The maximum proton energy in this case was 3.5 $\mathrm{MeV}$. The smaller proton energy in the case of lower contrast can be explained by the rear surface disruption and/or bending (Mackinnon et al. 2001; Lindau et al. 2005). Interestingly, when we adjusted the duration of the ASE in the lower-contrast case (no saturable absorber, contrast $\sim 5 \times 10^{6}$ ) by shifting the gating time of the Pockels Cell (PC) by 300 ps, the proton energy increased up to $4.1 \mathrm{MeV}$ in some shots; the preplasma size was in this case intermediate [Fig. 6 (b)]. The proton energy higher than in the case with the saturable absorber can be understood by larger laser power and intensity, which were achieved without the saturable absorber, by increased absorption in the preformed plasma (Gibbon \& Bell 1992; Borghesi et al. 1999; Ping et al. 2008; Pirozhkov et al. 2009a), and by the laser pulse self-focusing in the preplasma with the optimum scale length (Bychenkov et al. 2001; McKenna et al. 2008).

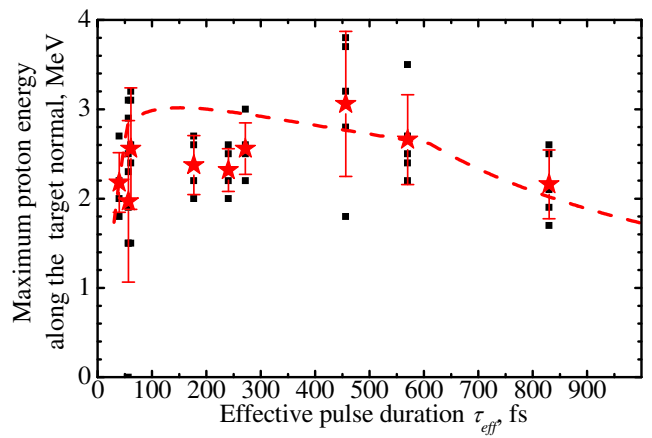

Fig. 5. Maximum proton energy at $0^{\circ}$ (along the target normal) vs. the effective pulse duration $\tau_{e f f}$. The target is $7.5 \mu \mathrm{m}$ polyimide tape, the saturable absorber is not used. The individual shots are shown with the squares, the several-shot average with the stars and the error bars (the standard deviation of shot-to-shot fluctuations). The dashed line shows the calculated dependence; the model used for the calculation is described in (Fuchs et al. 2006) with the additional limitation of the acceleration length equals the sheath diameter (Robson et al. 2007).

Taking advantage of the repetitive operation, we studied the stability of the proton acceleration (Fig. 8). Although the case with the optimum preplasma allowed achieving higher proton energies in some shots, the proton acceleration was less stable than in the case of high laser contrast. We measured the maximum proton energies at the target normal direction $\left(0^{\circ}\right)$ and at $22.5^{\circ}$ from normal in 13 (40) consecutive shots without (with) the saturable absorber. In the case of higher contrast, the average proton energy was higher and fluctuations were smaller, which is important for many applications requiring stable ion beam. Further, in the high-contrast case the maximum proton energy at $0^{\circ}$ was always larger than at $22.5^{\circ}$. In the case of lower contrast, the shot-to-shot fluctuations were large, and the maximum proton energies at these two angles were nearly same. Instability of the proton acceleration in the lower contrast case can be explained by the unstable nature of the preplasma itself, as well as relativistic self-focusing, which is also a kind of instability 
(Litvak 1970). Angular distributions of proton beam at different contrast conditions are described in details in (Yogo et al. 2008).
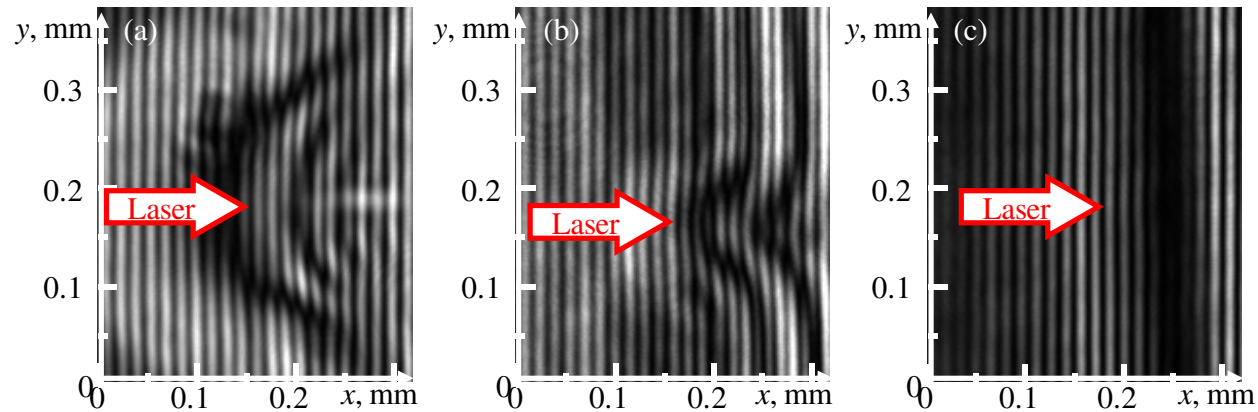

Fig. 6. Preplasma diagnostic using the interferometry with $820 \mathrm{~nm}$ femtosecond probe pulses 50 ps before the main laser pulse. The target is $7.5 \mu \mathrm{m}$ thick polyimide tape. The three different laser operation modes with different contrasts are used: (a) without the saturable absorber, 3-stage OPCPA, (thin red line in Fig. 3), Pockels Cell (PC) voltage on at -1 ns; (b) same as (a), but the PC voltage on @- 0.7 ns (corresponds to the ASE duration shorter by 0.3 ns); (c) with the saturable absorber and 2-stage non-saturated OPCPA (thick green line in Fig. 3), PC off (corresponds to the ASE duration of $\sim 3 \mathrm{~ns}$ ).

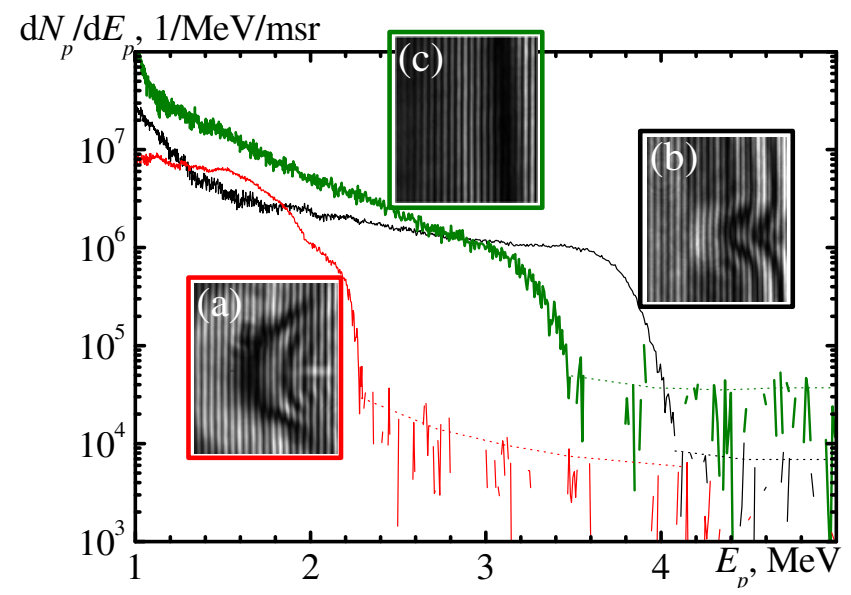

Fig. 7. Proton energy spectra at several modes of laser operation with different contrasts: The thin red line corresponds to the mode with the CPA oscillator, no saturable absorber, and 3-stage OPCPA (thin red line in Fig. 3). The thin black line corresponds to same case but with the shorter by 0.3 ns ASE duration (also thin red line in Fig. 3, because the contrast is not affected significantly by the Pockels Cell within the measurement range of $-0.5 \ldots+0.1$ $\mathrm{ns}$ ). The thick green line corresponds to the mode with the saturable absorber and 2-stage (nonsaturated) OPCPA (thick green line in Fig. 3). The dotted lines show the characteristic noise levels in the corresponding ToF spectra. The interferograms taken in the same shots [Fig. 6(a) - (c)] are shown near the spectra. 

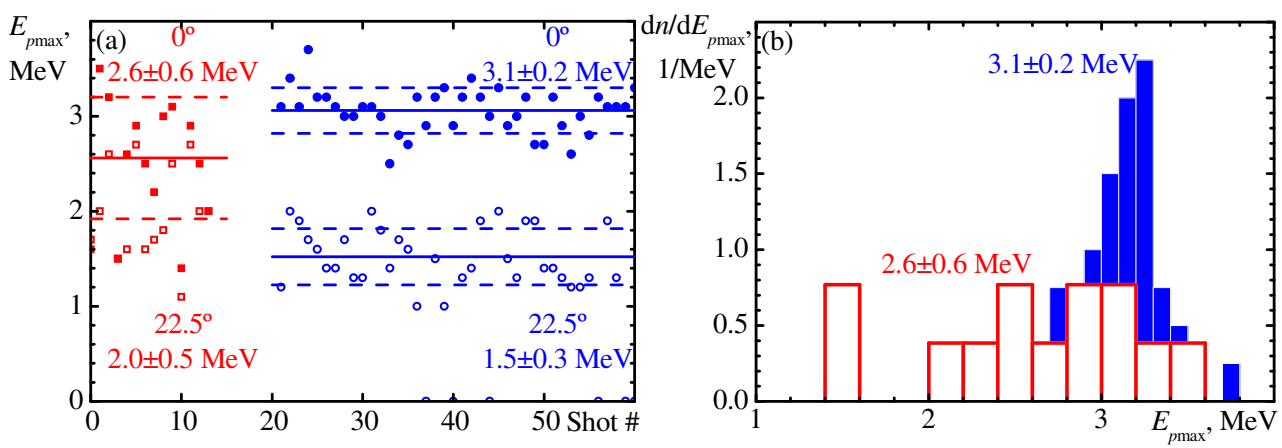

Fig. 8. Maximum proton energy in the consecutive shots with the same shooting parameters, the repetitive proton acceleration at $1 \mathrm{~Hz}$ employing the $7.5 \mu \mathrm{m}$ thick polyimide tape target.

(a) Maximum proton energy vs. shot number; solid symbols correspond to observation at $0^{\circ}$ (along the target normal direction), open symbols at $22.5^{\circ}$ off the normal in the same shots. Blue circles (red squares) correspond to the case with (without) the saturable absorber (in both cases, 3-stage OPCPA is used). (b) The histograms of maximum proton energy distributions at $0^{\circ}$ (along the target normal) corresponding to the frame (a).

It has been shown in simulations (Esirkepov et al. 2006) and experiments (Neely et al. 2006; Antici et al. 2007; Ceccotti et al. 2007) that very thin (sub-micrometer to nanometer-scale) targets can provide higher proton energy and larger conversion efficiency, provided that the laser contrast is sufficiently high so that the target is not damaged by the preceding light. We compared the proton acceleration from ribbon targets with the thickness from $1 \mu \mathrm{m}$ to $200 \mathrm{~nm}$. The proton energies from $1 \mu \mathrm{m}$ thick Au targets were larger than from thinner targets (Fig. 9). Although the nanosecond contrast was sufficiently high, the target was probably disturbed by the picosecond pedestal or prepulses at few tens of picoseconds before the main pulse (Fig. 3).

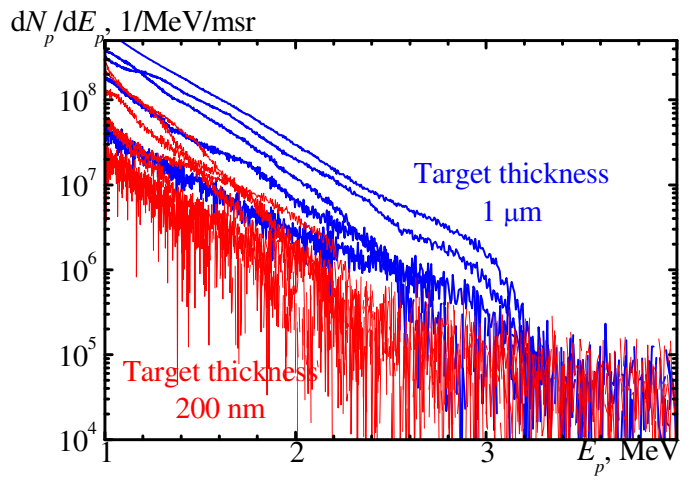

Fig. 9. Proton energy spectra at the target normal direction in several shots with different targets. The saturable absorber is used, 2-stage not-saturated OPCPA, Pockels Cell voltage off ( $3 \mathrm{~ns}$ ASE). The thick blue lines correspond to the $1 \mu \mathrm{m}$ thick Au targets; the thin red lines correspond to the $200 \mathrm{~nm}$ thick $\mathrm{Pd}, \mathrm{Pt}$, and $\mathrm{Au}$ targets. 


\section{On the contrast of high-power lasers}

The laser contrast strongly affects ion acceleration. In particular, in the TNSA regime higher ion energy is expected from thinner target in the ideal case, but in real experiments the rear surface of very thin targets is perturbed due to the preplasma formation, so there is an optimum target thickness (Kaluza et al. 2004). The ASE can even turn the originally soliddensity target into a near-critical density plasma cloud (Matsukado et al. 2003; Yogo et al. 2008), so the acceleration mechanism changes, and the ions are accelerated by a long-living charge separation electric field, sustained by a quasistatic magnetic field of dipole vortex (Bulanov et al. 2005; Bulanov \& Esirkepov 2007; Fukuda et al. 2009).

In order to understand the influence of the laser contrast in the described experiments, we performed the laser contrast diagnostics based on the target reflectivity measurement. The reflectivity was measured using calibrated calorimeters at full power operation in the real shooting conditions. The detailed description of this technique and experiments performed at three different laser systems can be found in (Pirozhkov et al. 2009a; Pirozhkov et al. 2009b). The data obtained with J-KAREN laser are shown in Fig. 10.
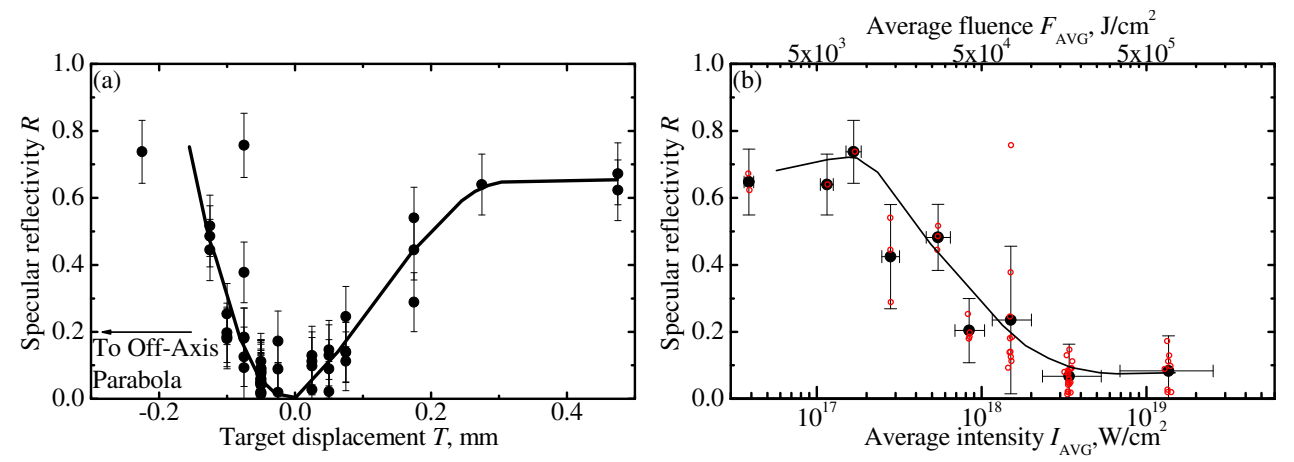

Fig. 10. On-target contrast diagnostic using the reflectivity of solid target at full laser power. The specular reflectivity $R$ is measured with the in-vacuum calibrated calorimeter (Fig. 4). The spot size is varied by moving the target by distance $T$ from best focus, the distance is measured along the laser beam, $T<0$ corresponds to the target shifted toward the Off-Axis Parabola (OAP). (a) Specular reflectivity $R$ vs. target position $T$. The error bars include the calibration errors and measured noise. (b) $R$ vs. derived average intensity (bottom axis) and fluence (top axis) (the average over the FWHM spot area, accounting for the $45^{\circ}$ incidence angle). The red open circles are the single-shot data, the black filled circles are the average values; the horizontal error bars are due to the target zero position uncertainty; the vertical error bars include shot-to-shot fluctuations, calibration errors, and measured noise.

The data were taken with the saturable absorber present and 3-stage OPCPA, the contrast was $\sim 5 \times 10^{8}$ with the ASE duration of $3 \mathrm{~ns}$. The dependence of the reflectivity on the target position [Fig. 10 (a)] exhibits a dip at best focus position $T=0$. Such dip corresponds to the insufficient laser contrast. The specular reflectivity decreases due to both the increased absorption in the preplasma and the beam break-up. The dependence of the reflectivity on the average intensity and fluence [Fig. 10 (b)] shows that the reflectivity was still high at the average intensity of $\sim 2 \times 10^{17} \mathrm{~W} / \mathrm{cm}^{2}$, which is $\sim 100$ times smaller than the intensity at best focus. Therefore, $\mathrm{a} \sim 100$-fold improvement of the contrast was necessary to avoid the 
preplasma formation by the ASE. This factor had been achieved by using non-saturated (2stage) OPCPA operation, which was used to shoot sub- $\mu \mathrm{m}$ targets (Fig. 9). However, in the latter case the picosecond pedestal or prepulses might be able to produce the preplasma, which led to the decreased proton energies observed in the case of $200 \mathrm{~nm}$ targets.

\section{Focusing of laser-driven proton beams with the permanent magnet quadrupoles}

The perspective mechanisms of laser-driven ion acceleration promise to provide quasimonoenergetic, low-divergence ion beams (Kuznetsov et al. 2001; Esirkepov et al. 2004; Esirkepov et al. 2006). However, in the present experiments the typical ion beam divergence is $\sim 10^{\circ}$, and the energy spectrum is wide (energy spread $\sim 100 \%$ ) (Borghesi et al. 2006). This is disadvantageous for many applications of the laser-driven ion beams, which are possible at present. Here we can point out the radiobiological studies (Yogo et al. 2009), ion beam injector to the postaccelerator (Krushelnick et al. 2000; Cowan et al. 2004), etc. Therefore, it would be desirable to modify the ion beam divergence and spectrum. There were several proposals and demonstrations of various techniques, including the use of a curved target (Bulanov et al. 2000; Sentoku et al. 2000; Ruhl et al. 2001; Patel et al. 2003) (focusing or collimation of the proton beam), laser-driven plasma microlens (Toncian et al. 2006) (proton beam focusing and energy selection), phase rotation using a radio-frequency electric field (Nakamura et al. 2007; Ikegami et al. 2009; Wakita et al. 2009) (modification of the proton energy spectrum and beam divergence), and use of permanent magnet quadrupoles (PMQs) (Schollmeier et al. 2008; Ter-Avetisyan et al. 2008; Nishiuchi et al. 2009) (focusing or collimation of the ion beam, energy band selection). In this Section, we describe the experiment in which the efficient proton beam manipulation with the PMQs was demonstrated (Nishiuchi et al. 2009). The feature of this experiment is the $1 \mathrm{~Hz}$ repetition rate and the large acceptance angle of the PMQs, which allowed achieving high proton flux. The experiment was performed with J-KAREN laser with the on-target pulse energy of $0.7 \mathrm{~J}$, pulse duration of $30 \mathrm{fs}$, peak irradiance of $\sim 10^{20} \mathrm{~W} / \mathrm{cm}^{2}$, and the ASE contrast and duration of $10^{7}$ and $1 \mathrm{~ns}$, respectively. The setup was similar to the one shown in Fig. 4 . However, the pair of PMQs was installed at the target rear side, as shown in Fig. 11.

Originally, the proton beam with the energy band from 1.9 to $2.8 \mathrm{MeV}$ had a typical divergence of $10^{\circ}$ (half angle), as it is demonstrated in the frame (a). The acceptance angle of the first PMQ was also $\sim 10^{\circ}$ (half angle). Thus, nearly all protons were accepted at this stage. The first PMQ focused the protons in the vertical and defocused in the horizontal planes. Due to the defocusing, some of the protons were not collected with the second PMQ. Those protons which were collected were further focused in the horizontal and defocused in the vertical planes with the second PMQ. As a result, the focus point was formed at the distance of $650 \mathrm{~mm}$ from the target. The proton beam profiles recorded with the CR-39 nuclear track detectors at the best focus as well as several other positions are shown in the frames (b) - (g) of Fig. 11 (the proton energy range is 2.2 to $3.1 \mathrm{MeV}$ ). At the best focus, the CR-39 image has the dimensions of $\sim 3 \mathrm{~mm} \times 8 \mathrm{~mm}$. However, due to the etch pit overlapping (detector saturation), this visible spot size is overestimated, and the real spot was smaller.

Apart from the proton beam profile, we also measured the proton energy spectra with the ToF spectrometer situated at $1.93 \mathrm{~m}$ from the target. The original spectrum (without the PMQs) is shown in Fig. 12 (a) by the line 2. With the PMQs, the spectrum becomes quasimonoenergetic due to the strong chromatic aberrations of the PMQs (namely, most of the 


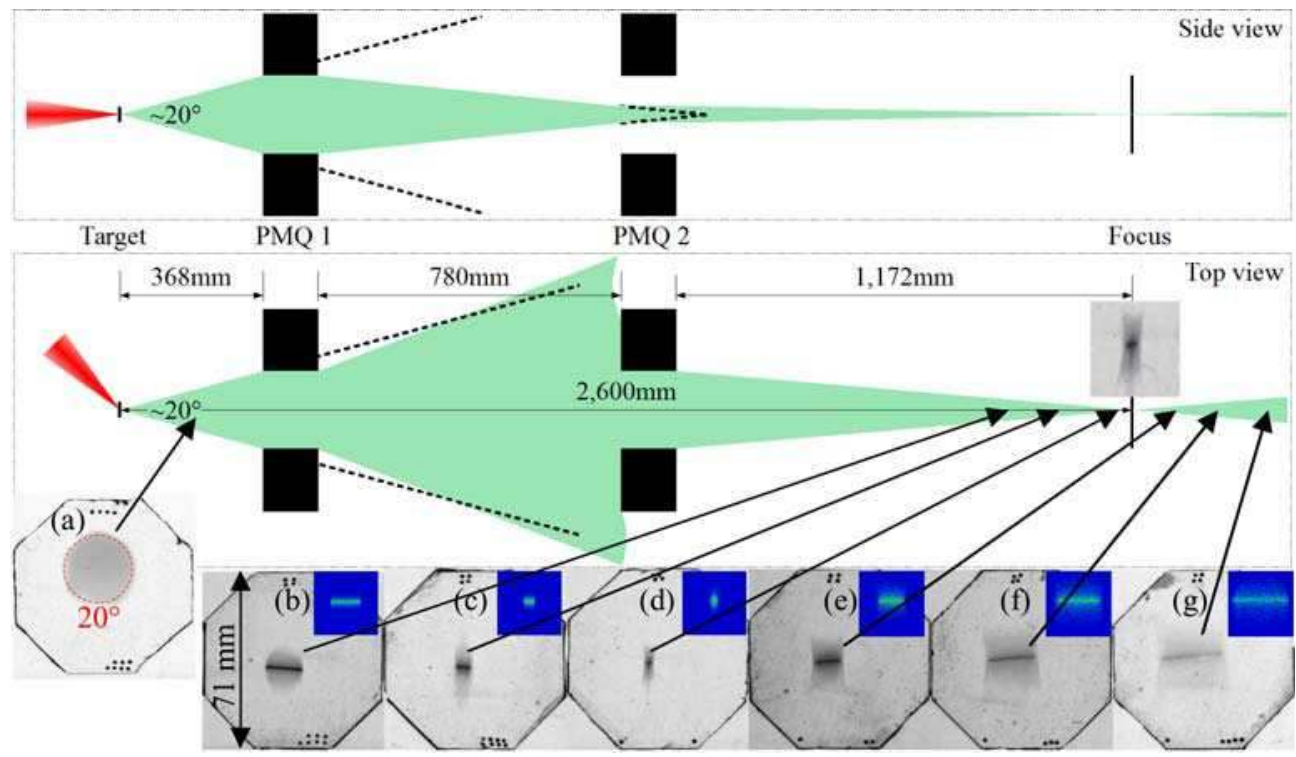

Fig. 11. Focusing of the laser-driven proton beam with two permanent magnet quadrupoles (PMQs). Schematic layout of the setup is shown in the vertical (side view) and the horizontal (top view) planes. The first PMQ has the field gradient of $55 \mathrm{~T} / \mathrm{m}$, thickness of $50 \mathrm{~mm}$, and open diameter of $35 \mathrm{~mm}$; the acceptance half-angle is $\sim 10^{\circ}$, which is similar to the proton beam divergence. The second PMQ parameters are the field gradient of $60 \mathrm{~T} / \mathrm{m}$, thickness of $20 \mathrm{~mm}$, and diameter of $23 \mathrm{~mm}$. The octagonal frames (a) - (g) at the bottom of the figure show the experimental results obtained with $12.5 \mu \mathrm{m}$ polyimide tape target; the proton beam profiles are recorded with the CR-39 nuclear track detectors covered with the Al range filter, the darker regions correspond to the higher proton density. The left CR-39 picture [frame (a)] is the original beam profile before the PMQs ( $\mathrm{Al} 40 \mu \mathrm{m}$ filter, 1.9 to $2.8 \mathrm{MeV}$ ). The frames (b) - (g) show the proton beam profiles at 450, 550, 650 (best focus), 750, 850, and 927 $\mathrm{mm}$ from the target $(2.2$ to $3.1 \mathrm{MeV})$. At the best focus [650 $\mathrm{mm}$, frame (d)], the visible beam size is $\sim 3 \mathrm{~mm} \times 8 \mathrm{~mm}$; these dimensions are overestimated due to the CR-39 saturation (etch pit overlapping) at the center of the image. The proton beam profiles in the blue insets on the frames (b) - (g) are obtained using the Monte-Carlo simulations; the spatial scales are the same as in the CR-39 images.

low-energy protons, except those near the axis, are strongly deflected by the first PMQ and do not pass through the aperture of the second PMQ).

Each frame (b) - (g) in Fig. 11 also contains the inset, which shows the result of the MonteCarlo simulation of the proton beam profile at the corresponding position. The parameters of the original proton beam (spectrum, divergence) and the beam transport system in the simulation was set in accordance with the experimental conditions. The close similarity of the experimental beam profiles with the simulation suggests that the alignment accuracy was sufficient in the experiment; we found that the accuracy of the magnet positioning should be $\sim 100 \mu \mathrm{m}$. Additional evidence of the similarity is shown in Fig. 12 (a), where the spectrum measured with the ToF is compared with the simulated one. The similarity of the experimental results and the simulation allows us to derive conclusions about the detailed 
parameters of the focused proton beam. In particular, we can simulate the proton energy spectrum at the focal plane (this is not same as the spectrum measured with the ToF at the distance of $1.93 \mathrm{~m}$ ). The simulated spectrum is shown in Fig. 12 (b); here the protons passing through the $3 \mathrm{~mm}$ diameter aperture are included. The spectrum is quasi-monoenergetic, with the energy of $2.4 \pm 0.1 \mathrm{MeV}$. The transport efficiency of the beamline for the energy range of $2.3-2.5 \mathrm{MeV}$ was 0.3 . The loss was due to the second PMQ, as shown in the schematic layout in Fig. 11. The efficiency of 0.3 should be compared with the transport efficiency of the divergent beam without the PMQs, which is $\sim 1.7 \times 10^{-4}\left(1.7 \times 10^{3}\right.$ times smaller). Simulation also allowed calculating the duration of the proton bunch, which was $\sim 1 \mathrm{~ns}$. This is much shorter than the typical achievable value, which is determined by the strong dispersion of the usual proton beam with a large energy spread.

The passive nature of the magnetic beamline led to the high stability of the spectrum after the PMQ pair. The pointing stability of the proton beam was $0.25 \pm 0.1^{\circ}$ (standard deviation of shot-to-shot fluctuations). The instability of the proton number within the energy range of $2.4 \pm 0.1 \mathrm{MeV}$ was $20 \%$; this value included the fluctuations of the proton number, divergence, and pointing of the proton beam during the acceleration stage, originating from the laser, target, and plasma instabilities.

The demonstrated technique of the ion beam focusing can be useful in many applications of the laser-driven ion beams, including such field as high-energy density physics, radiography, nuclear physics, astrophysics, radiobiological studies, chemistry, material sciences, etc.

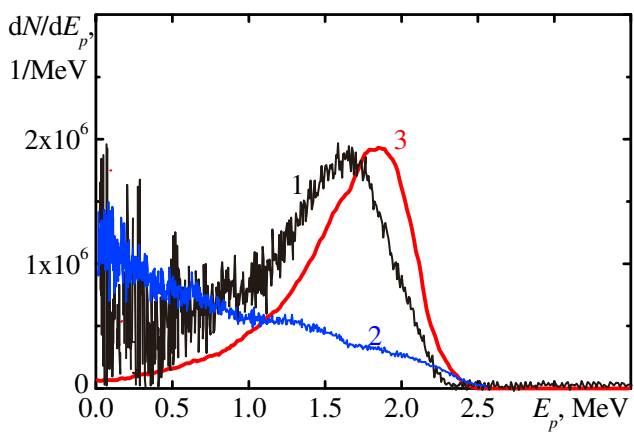

(a)

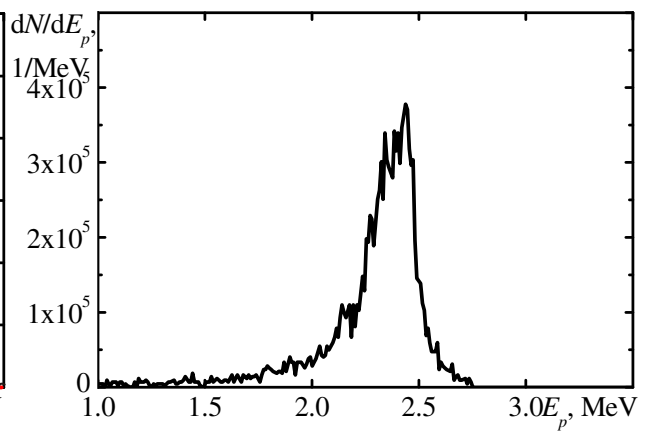

(b)

Fig. 12. (a) The black line (1) is the spectrum of the proton beam focused with the PMQs; the spectrum is measured with the absolutely-calibrated Time-Of-Flight (ToF) spectrometer at the distance of $1.93 \mathrm{~m}$ from the target. The blue line (2) is the original spectrum (without the PMQs) at the same ToF position. The red line (3) is the simulated spectrum at the TOF position. (b) Proton energy spectrum within the $3 \mathrm{~mm}$ diameter circular aperture at the focal plane (simulation).

\section{Radioactivation experiments}

Multi-MeV laser-driven proton beams can induce nuclear reactions (Ledingham et al. 2003; McKenna et al. 2003). In fact, these nuclear reactions were used for the proton beam diagnostic in many experiments (Hatchett et al. 2000; Snavely et al. 2000; McKenna et al. 
2004; Clarke et al. 2008). Another possible application of the nuclear reactions induced by laser-driven proton beams is the thin layer activation (TLA) (Racolta et al. 1995), which allows studying the wear of tools, for example cutting tools made from cubic boron nitride (BN) or artificial polycrystalline diamond (DIA) (Conlon 1985; Vasváry et al. 1994). In TLA, the thin layer of tool is activated by selecting the appropriate energy range of the proton beam. Measuring the residual activity, it is possible to determine the loss of the surface material with the high sensitivity. Various isotopes can be activated, including iron, titanium, chromium, etc., which opens wide possibilities for the industrial diagnostic. The typical reaction threshold is from few to $10 \mathrm{MeV}$, which means that compact laser systems can be used.

In this Section, we describe the results of the proof-of-principle experiment on the BN target activation (Ogura et al. 2009). The experimental setup is shown in Fig. 13 (a). The parameters of J-KAREN laser used in this experiment were as follows: the pulse energy of $\sim 1 \mathrm{~J}$, the pulse duration of $30 \mathrm{fs}$, the peak irradiance of $\sim 10^{20} \mathrm{~W} / \mathrm{cm}^{2}$, the ASE contrast of higher than $10^{10}$. The target for the laser was polyimide tape. At the rear side of the tape, the BN sample was installed. The laser-driven proton beam induced the reaction ${ }^{11} \mathrm{~B}(\mathrm{p}, \mathrm{n}){ }^{11} \mathrm{C}$, which has the threshold of $2.76 \mathrm{MeV}$. The maximum proton energy in this experiment ranged from 2.8 to 3.5 MeV, larger than the reaction threshold.
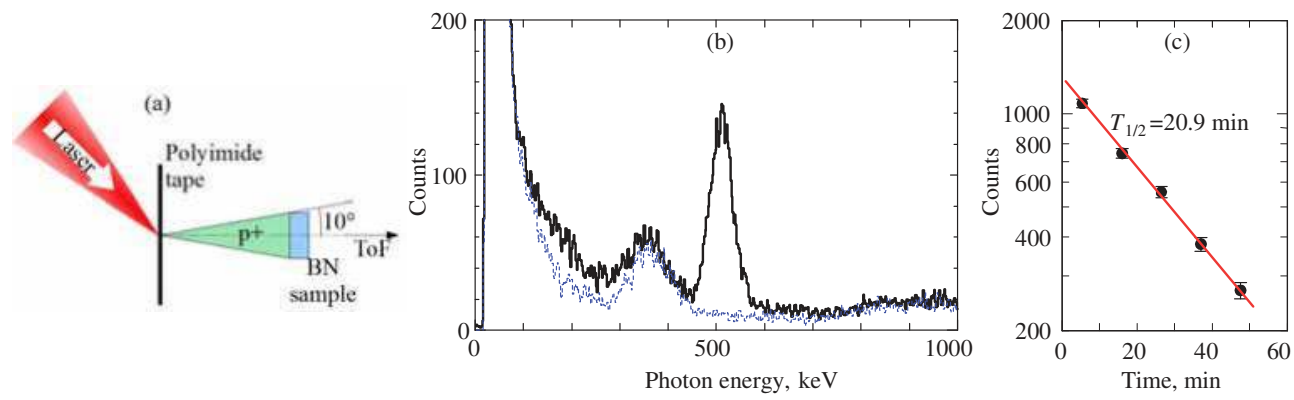

Fig. 13. (a) Experimental setup for irradiation of $B N$ sample with the laser-driven proton beam. (b) Radiation spectrum measured using GSO $\left[\mathrm{Gd}_{2} \mathrm{SiO}_{5}(\mathrm{Ce})\right]$ scintillation counter (solid line). The blue dotted line denotes the background. (c) The decay curve of annihilation photons with the fitted half-life time of $T_{1 / 2}=20.9 \pm 0.7 \mathrm{~min}$, which corresponds to the decay of ${ }^{11} \mathrm{C}\left(T_{1 / 2}=20.39 \pm 0.02 \mathrm{~min}\right)$.

The isotopes ${ }^{11} \mathrm{C}$ produced in the nuclear reaction decay through the positron emission with the half-life time $T_{1 / 2}=20.39 \pm 0.02 \mathrm{~min}$ (ENSDF, NNDC Online Data Service, ENSDF database [http://www.nndc.bnl.gov/ensdf/]). The positrons annihilate with the emission of two photons with the energy of $0.511 \mathrm{MeV}$, directed at $180^{\circ}$ to each other. The annihilation photon spectrum recorded with the GSO scintillation counter (Leo 1987) is shown in Fig. 13 (b). From the decay curve shown in the inset, the half-life time can be deduced: $T_{1 / 2}=20.9 \pm 0.7 \mathrm{~min}$, which corresponds to the decay time of ${ }^{11} \mathrm{C}$. After 60 laser shots, the activity of the sample was measured to be $11.1 \pm 0.4 \mathrm{~Bq}$. Using the $10 \mathrm{~Hz}$ laser operation during 10 minutes (6000 shots), the activity in the $\mathrm{kBq}$ range can be obtained, which is sufficient for the typical TLA diagnostic. Finally, we note that, unlike the situation with many other applications, the large divergence angle and the broad energy spectrum of 
the laser-induced proton beam can be convenient for the thin layer activation industrial diagnostic.

\section{Conclusion}

In conclusion, the laser-driven ion acceleration is the perspective new technique. The laserdriven ion beams have unique properties, such as ultrashort bunch duration, low emittance, small source size, and large particle number. The laser-driven acceleration is a very compact process, which takes place on the micrometer scale. For many applications, a repetitive ion beam is desirable, which can be achieved employing femtosecond laser systems. We described the performance of laser and properties of proton beam by the example of experiments performed in the Advanced Photon Research Center, Japan Atomic Energy Agency with J-KAREN laser. In particular, we described the dependence of the maximum proton energy on the laser pulse duration and found the optimum of few hundred femtoseconds for the given experimental conditions. We also depicted the influence of laser contrast and demonstrated the method of its diagnostic. We described two application experiments, in which the stable, repetitive $(1 \mathrm{~Hz})$ laser-driven proton beam was focused by the permanent magnet quadrupoles, and was used for the BN target activation, which can be applicable in the industrial testing of tools and mechanisms using the thin layer activation technique.

\section{Acknowledgments}

We are grateful for the expert support of J-KAREN laser team. This work was supported by the Special Coordination Funds for Promoting Science and Technology (SCF) commissioned by the Ministry of Education, Science, Sports and Culture (MEXT) of Japan and partly by Specially Promoted Education and Research by MEXT.

\section{References}

Antici, P., Fuchs, J., d'Humieres, E., Lefebvre, E., Borghesi, M., Brambrink, E., Cecchetti, C. A., Gaillard, S., Romagnani, L., Sentoku, Y., Toncian, T., Willi, O., Audebert, P. \& Pepin, H. (2007). Energetic protons generated by ultrahigh contrast laser pulses interacting with ultrathin targets. Phys. Plasmas, 14, 3, (Mar) 030701, 1070-664X

Borghesi, M., Mackinnon, A. J., Gaillard, R., Willi, O. \& Riley, D. (1999). Absorption of subpicosecond uv laser pulses during interaction with solid targets. Phys. Rev. E, 60, 6, (Dec) 7374-7381, 1063-651X

Borghesi, M., Schiavi, A., Campbell, D. H., Haines, M. G., Willi, O., MacKinnon, A. J., Gizzi, L. A., Galimberti, M., Clarke, R. J. \& Ruhl, H. (2001). Proton imaging: a diagnostic for inertial confinement fusion/fast ignitor studies. Plasma Phys. Control. Fusion, 43, 12A A267, 0741-3335

Borghesi, M., Fuchs, J., Bulanov, S. V., Mackinnon, A. J., Patel, P. K. \& Roth, M. (2006). Fast ion generation by high-intensity laser irradiation of solid targets and applications. Fus. Sci. Tech., 49, 3, (Apr) 412-439, 1536-1055

Bulanov, S. V., Esirkepov, T. Zh., Califano, F., Kato, Y., Liseikina, T. V., Mima, K., Naumova, N. M., Nishihara, K., Pegoraro, F., Ruhl, H., Sentoku, Y. \& Ueshima, Y. (2000). 
Generation of collimated beams of relativistic ions in laser-plasma interactions. JETP Lett., 71, 10 407-411, 0021-3640 (Print) 1090-6487 (Online)

Bulanov, S. V., Esirkepov, T. Zh, Khoroshkov, V., Kuznetsov, A. \& Pegoraro, F. (2002). Oncological hadrontherapy with laser ion accelerators. Phys. Lett. A, 299, 2-3 240247

Bulanov, S. V. \& Khoroshkov, V. S. (2002). Feasibility of using laser ion accelerators in proton therapy. Plas. Phys. Rep., 28, 5 453-456

Bulanov, S. V., Dylov, D., Esirkepov, T. Zh., Kamenets, F. \& Sokolov, D. (2005). Ion acceleration in a dipole vortex in a laser plasma corona. Plas. Phys. Rep., 31, 5, (May) 369-381, 1063-780X (Print) 1562-6938 (Online)

Bulanov, S. V. \& Esirkepov, T. Zh. (2007). Comment on “Collimated Multi-MeV Ion Beams from High-Intensity Laser Interactions with Underdense Plasma". Phys. Rev. Lett., 98, 4, (24 January) 049503-1

Bychenkov, V. Y., Sentoku, Y., Bulanov, S. V., Mima, K., Mourou, G. \& Tolokonnikov, S. V. (2001). Pion production under the action of intense ultrashort laser pulse on a solid target. JETP Lett., 74, 12 586-589

Ceccotti, T., Levy, A., Popescu, H., Reau, F., D'Oliveira, P., Monot, P., Geindre, J. P., Lefebvre, E. \& Martin, P. (2007). Proton acceleration with high-intensity ultrahighcontrast laser pulses. Phys. Rev. Lett., 99, 18, (Nov 2) 185002, 0031-9007

Clarke, R. J., Simpson, P. T., Kar, S., Green, J. S., Bellei, C., Carroll, D. C., Dromey, B., Kneip, S., Markey, K., McKenna, P., Murphy, W., Nagel, S., Willingale, L. \& Zepf, M. (2008). Nuclear activation as a high dynamic range diagnostic of laser-plasma interactions. Nucl. Instr. Methods Phys. Res. Sect. A, 585, 3, (Feb 1) 117-120, 0168-9002

Conlon, T. W. (1985). Nuclear physics for materials technology accelerator based methods? Contemporary Physics, 26, 6, (November) 521 - 558, 0010-7514

Cowan, T. E., Fuchs, J., Ruhl, H., Kemp, A., Audebert, P., Roth, M., Stephens, R., Barton, I., Blazevic, A., Brambrink, E., Cobble, J., Fernández, J., Gauthier, J. C., Geissel, M., Hegelich, M., Kaae, J., Karsch, S., Le Sage, G. P., Letzring, S., Manclossi, M., Meyroneinc, S., Newkirk, A., Pūpin, H. \& Renard-LeGalloudec, N. (2004). Ultralow Emittance, Multi-MeV Proton Beams from a Laser Virtual-Cathode Plasma Accelerator. Phys. Rev. Lett., 92, 20204801

Esirkepov, T. Zh., Borghesi, M., Bulanov, S. V., Mourou, G. \& Tajima, T. (2004). Highly Efficient Relativistic-Ion Generation in the Laser-Piston Regime. Phys. Rev. Lett., 92, 17175003

Esirkepov, T. Zh., Yamagiwa, M. \& Tajima, T. (2006). Laser Ion-Acceleration Scaling Laws Seen in Multiparametric Particle-in-Cell Simulations. Phys. Rev. Lett., 96, 10 1050014

Fritzler, S., Malka, V., Grillon, G., Rousseau, J. P., Burgy, F., Lefebvre, E., d'Humieres, E., McKenna, P. \& Ledingham, K. W. D. (2003). Proton beams generated with highintensity lasers: Applications to medical isotope production. Appl. Phys. Lett., 83, 15 3039-3041

Fuchs, J., Antici, P., D'Humieres, E., Lefebvre, E., Borghesi, M., Brambrink, E., Cecchetti, C. A., Kaluza, M., Malka, V., Manclossi, M., Meyroneinc, S., Mora, P., Schreiber, J., Toncian, T., Pepin, H. \& Audebert, R. (2006). Laser-driven proton scaling laws and new paths towards energy increase. Nature Phys., 2, 1, (Jan) 48-54, 1745-2473 
Fukuda, Y., Faenov, A. Y., Tampo, M., Pikuz, T. A., Nakamura, T., Kando, M., Hayashi, Y., Yogo, A., Sakaki, H., Kameshima, T., Pirozhkov, A. S., Ogura, K., Mori, M., Esirkepov, T. Zh., Koga, J., Boldarev, A. S., Gasilov, V. A., Magunov, A. I., Yamauchi, T., Kodama, R., Bolton, P. R., Kato, Y., Tajima, T., Daido, H. \& Bulanov, S. V. (2009). Energy Increase in Multi-MeV Ion Acceleration in the Interaction of a Short Pulse Laser with a Cluster-Gas Target. Phys. Rev. Lett., 103, 16, (13 October) 165002-4

Gibbon, P. \& Bell, A. R. (1992). Collisionless Absorption in Sharp-Edged Plasmas. Phys. Rev. Lett., 68, 10, (Mar 9) 1535-1538, 0031-9007

Hatchett, S. P., Brown, C. G., Cowan, T. E., Henry, E. A., Johnson, J. S., Key, M. H., Koch, J. A., Langdon, A. B., Lasinski, B. F., Lee, R. W., Mackinnon, A. J., Pennington, D. M., Perry, M. D., Phillips, T. W., Roth, M., Sangster, T. C., Singh, M. S., Snavely, R. A., Stoyer, M. A., Wilks, S. C. \& Yasuike, K. (2000). Electron, photon, and ion beams from the relativistic interaction of Petawatt laser pulses with solid targets. Phys. Plasmas, 7, (May) 2076-2082

Hegelich, M., Karsch, S., Pretzler, G., Habs, D., Witte, K., Guenther, W., Allen, M., Blazevic, A., Fuchs, J., Gauthier, J. C., Geissel, M., Audebert, P., Cowan, T. \& Roth, M. (2002). MeV Ion Jets from Short-Pulse-Laser Interaction with Thin Foils. Phys. Rev. Lett., 89, 8, (2 August) 085002

Henig, A., Kiefer, D., Markey, K., Gautier, D. C., Flippo, K. A., Letzring, S., Johnson, R. P., Shimada, T., Yin, L., Albright, B. J., Bowers, K. J., Fernandez, J. C., Rykovanov, S. G., Wu, H. C., Zepf, M., Jung, D., Liechtenstein, V. K., Schreiber, J., Habs, D. \& Hegelich, B. M. (2009). Enhanced Laser-Driven Ion Acceleration in the Relativistic Transparency Regime. Phys. Rev. Lett., 103, 4, (21 July) 045002-4

Ikegami, M., Nakamura, S., Iwashita, Y., Shirai, T., Souda, H., Tajima, Y., Tanabe, M., Tongu, H., Itoh, H., Shintaku, H., Yamazaki, A., Daido, H., Yogo, A., Orimo, S., Mori, M., Nishiuchi, M., Ogura, K., Sagisaka, A., Pirozhkov, A. S., Kiriyama, H., Kanazawa, S., Kondo, S., Yamamoto, Y., Shimomura, T., Tanoue, M., Nakai, Y. \& Akutsu, A. (2009). Radial focusing and energy compression of a laser-produced proton beam by a synchronous rf field. Phys. Rev. STAB, 12, 6 063501-6

Kaluza, M., Schreiber, J., Santala, M. I. K., Tsakiris, G. D., Eidmann, K., Meyer-ter-Vehn, J. \& Witte, K. J. (2004). Influence of the Laser Prepulse on Proton Acceleration in ThinFoil Experiments. Phys. Rev. Lett., 93, 4, (20 July) 045003

Kiriyama, H., Mori, M., Nakai, Y., Shimomura, T., Tanoue, M., Akutsu, A., Kondo, S., Kanazawa, S., Okada, H., Motomura, T., Daido, H., Kimura, T. \& Tajima, T. (2008). High-contrast, high-intensity laser pulse generation using a nonlinear preamplifier in a Ti : sapphire laser system. Opt. Lett., 33, 7, (Apr 1) 645-647, 0146-9592

Kiriyama, H., Mori, M., Nakai, Y., Shimomura, T., Tanoue, M., Akutsu, A., Okada, H., Motomura, T., Kondo, S., Kanazawa, S., Sagisaka, A., Ma, J., Daito, I., Kotaki, H., Daido, H., Bulanov, S. V., Kimura, T. \& Tajima, T. (2009). Generation of highcontrast and high-intensity laser pulses using an OPCPA preamplifier in a double CPA, Ti:sapphire laser system. Opt. Comm., 282, 4, (Feb 15) 625-628, 0030-4018

Krushelnick, K., Clark, E. L., Allott, R., Beg, F. N., Danson, C. N., Machacek, A., Malka, V., Najmudin, Z., Neely, D., Norreys, P. A., Salvati, M. R., Santala, M. I. K., Tatarakis, M., Watts, I., Zepf, M. \& Dangor, A. E. (2000). Ultrahigh-intensity laser-produced 
plasmas as a compact heavy ion injection source. IEEE Trans. on Plasma Sci., 28, 4 1184-1189, 0093-3813

Kuznetsov, A., Esirkepov, T. Zh., Kamenets, F. \& Bulanov, S. (2001). Efficiency of ion acceleration by a relativistically strong laser pulse in an underdense plasma. Plas. Phys. Rep., 27, 3 211-220, 1063-780X (Print) 1562-6938 (Online)

Ledingham, K. W. D., McKenna, P. \& Singhal, R. P. (2003). Applications for Nuclear Phenomena Generated by Ultra-Intense Lasers. Science, 300, 5622, (May 16, 2003) $1107-1111$

Leo, W. R. (1987). Techniques for nuclear and particle physics experiments, Springer-Verlag New York Inc., New York

Li, Z., Daido, H., Fukumi, A., Sagisaka, A., Ogura, K., Nishiuchi, M., Orimo, S., Hayashi, Y., Mori, M., Kado, M., Bulanov, S. V., Esirkepov, T. Zh., Oishi, Y., Nayuki, T., Fujii, T., Nemoto, K., Nakamura, S. \& Noda, A. (2006). Measurements of energy and angular distribution of hot electrons and protons emitted from a p- and s-polarized intense femtosecond laser pulse driven thin foil target. Phys. Plasmas, 13, 4, (18 April) 043104-6

Lindau, F., Lundh, O., Persson, A., McKenna, P., Osvay, K., Batani, D. \& Wahlstrom, C. G. (2005). Laser-accelerated protons with energy-dependent beam direction. Phys. Rev. Lett., 95, 17, (Oct 21) 175002, 0031-9007

Litvak, A. (1970). Finite-amplitude wave beams in a magnetoactive plasma. Sov. Phys. JETP., 30344

Mackinnon, A. J., Borghesi, M., Hatchett, S., Key, M. H., Patel, P. K., Campbell, H., Schiavi, A., Snavely, R., Wilks, S. C. \& Willi, O. (2001). Effect of plasma scale length on multi-MeV proton production by intense laser pulses. Phys. Rev. Lett., 86, 9, (Feb 26) 1769-1772, 0031-9007

Matsukado, K., Esirkepov, T. Zh., Kinoshita, K., Daido, H., Utsumi, T., Li, Z., Fukumi, A., Hayashi, Y., Orimo, S., Nishiuchi, M., Bulanov, S. V., Tajima, T., Noda, A., Iwashita, Y., Shirai, T., Takeuchi, T., Nakamura, S., Yamazaki, A., Ikegami, M., Mihara, T., Morita, A., Uesaka, M., Yoshii, K., Watanabe, T., Hosokai, T., Zhidkov, A., Ogata, A., Wada, Y. \& Kubota, T. (2003). Energetic Protons from a Few-Micron Metallic Foil Evaporated by an Intense Laser Pulse. Phys. Rev. Lett., 91, 21, (18 November) 215001

McKenna, P., Ledingham, K. W. D., McCanny, T., Singhal, R. P., Spencer, I., Santala, M. I. K., Beg, F. N., Krushelnick, K., Tatarakis, M., Wei, M. S., Clark, E. L., Clarke, R. J., Lancaster, K. L., Norreys, P. A., Spohr, K., Chapman, R. \& Zepf, M. (2003). Demonstration of Fusion-Evaporation and Direct-Interaction Nuclear Reactions using High-Intensity Laser-Plasma-Accelerated Ion Beams. Phys. Rev. Lett., 91, 7 075006

McKenna, P., Ledingham, K. W. D., Yang, J. M., Robson, L., McCanny, T., Shimizu, S., Clarke, R. J., Neely, D., Spohr, K., Chapman, R., Singhal, R. P., Krushelnick, K., Wei, M. S. \& Norreys, P. A. (2004). Characterization of proton and heavier ion acceleration in ultrahigh-intensity laser interactions with heated target foils. Phys. Rev. E, 70, 3, (21 September) 036405

McKenna, P., Carroll, D. C., Lundh, O., Nurnberg, F., Markey, K., Bandyopadhyay, S., Batani, D., Evans, R. G., Jafer, R., Kar, S., Neely, D., Pepler, D., Quinn, M. N., Redaelli, R., Roth, M., Wahlstrom, C. G., Yuan, X. H. \& Zepf, M. (2008). Effects of 
front surface plasma expansion on proton acceleration in ultraintense laser irradiation of foil targets. Laser and Particle Beams, 26, 4, (Dec) 591-596, 0263-0346

Mora, P. (2003). Plasma expansion into a vacuum. Phys. Rev. Lett., 90, 18, (May 9) 185002, 0031-9007

Mourou, G. A., Tajima, T. \& Bulanov, S. V. (2006). Optics in the relativistic regime. Rev. Mod. Phys., 78, 2, (Apr-Jun) 309-371, 0034-6861

Murakami, M., Demizu, Y., Niwa, Y., Miyawaki, D., Terashima, K., Arimura, T., Mima, M., Nagayama, S., Maeda, T., Baba, M., Akagi, T., Hishikawa, Y. \& Abe, M. (2009). Current status of the HIBMC and results of representative diseases, Proceedings of Laser-Driven Relativistic Plasmas Applied To Science, Industry And Medicine: 2nd International Symposium, pp. 400-415, Kyoto (Japan), 19-23 January 2009, AIP

Nakamura, S., Iwashita, Y., Noda, A., Shirai, T., Tongu, H., Fukumi, A., Kado, M., Yogo, A., Mori, M., Orimo, S., Ogura, K., Sagisaka, A., Nishiuchi, M., Hayashi, Y., Li, Z., Daido, H. \& Wada, Y. (2006). Real-time optimization of proton production by intense short-pulse laser with time-of-flight measurement. Jpn. J. Appl. Phys., 45, 3336, (Sep) L913-L916, 0021-4922

Nakamura, S., Ikegami, M., Iwashita, Y., Shirai, T., Tongui, H., Souda, H., Daido, H., Mori, M., Kado, M., Sagisaka, A., Ogura, K., Nishiuchi, M., Orimo, S., Hayashi, Y., Yogo, A., Pirozhkov, A. S., Bulanov, S. V., Esirkepov, T. Zh., Nagashima, A., Kimura, T., Tajima, T., Takeuchi, T., Fukumi, A., Li, Z. \& Noda, A. (2007). High-quality laserproduced proton beam realized by the application of a synchronous RF electric field. Jpn. J. Appl. Phys., 46, 29-32, (Aug) L717-L720, 0021-4922

Nayuki, T., Oishi, Y., Fujii, T., Nemoto, K., Kayoiji, T., Okano, Y., Hironaka, Y., Nakamura, K. G., Kondo, K. \& Ueda, K. (2003). Thin tape target driver for laser ion accelerator. Rev. Sci. Instr., 74, 7, (Jul) 3293-3296, 0034-6748

Neely, D., Foster, P., Robinson, A., Lindau, F., Lundh, O., Persson, A., Wahlstrom, C. G. \& McKenna, P. (2006). Enhanced proton beams from ultrathin targets driven by high contrast laser pulses. Appl. Phys. Lett., 89, 2, (Jul 10) 021502, 0003-6951

Nemoto, K., Maksimchuk, A., Banerjee, S., Flippo, K., Mourou, G., Umstadter, D. \& Bychenkov, V. Y. (2001). Laser-triggered ion acceleration and table top isotope production. Appl. Phys. Lett., 78, 5 595-597

Nishiuchi, M., Daido, H., Yogo, A., Orimo, S., Ogura, K., Ma, J., Sagisaka, A., Mori, M., Pirozhkov, A. S., Kiriyama, H., Bulanov, S. V., Esirkepov, T. Zh., Choi, I. W., Kim, C. M., Jeong, T. M., Yu, T. J., Sung, J. H., Lee, S. K., Hafz, N., Pae, K. H., Noh, Y. C., Ko, D. K., Lee, J., Oishi, Y., Nemoto, K., Nagatomo, H., Nagai, K. \& Azuma, H. (2008). Efficient production of a collimated $\mathrm{MeV}$ proton beam from a polyimide target driven by an intense femtosecond laser pulse. Phys. Plasmas, 15, 5, (22 May) 053104-10

Nishiuchi, M., Daito, I., Ikegami, M., Daido, H., Mori, M., Orimo, S., Ogura, K., Sagisaka, A., Yogo, A., Pirozhkov, A. S., Sugiyama, H., Kiriyama, H., Okada, H., Kanazawa, S., Kondo, S., Shimomura, T., Tanoue, M., Nakai, Y., Sasao, H., Wakai, D., Sakaki, H., Bolton, P., Choi, I. W., Sung, J. H., Lee, J., Oishi, Y., Fujii, T., Nemoto, K., Souda, H., Noda, A., Iseki, Y. \& Yoshiyuki, T. (2009). Focusing and spectral enhancement of a repetition-rated, laser-driven, divergent multi-MeV proton beam using permanent quadrupole magnets. Appl. Phys. Lett., 94, 6, (Feb 9) 061107, 0003-6951 
Ogura, K., Shizuma, T., Hayakawa, T., Yogo, A., Nishiuchi, M., Orimo, S., Sagisaka, A., Pirozhkov, A. S., Mori, M., Kiriyama, H., Kanazawa, S., Kondo, S., Nakai, Y., Shimoura, T., Tanoue, M., Akutsu, A., Motomura, T., Okada, H., Kimura, T., Oishi, Y., Nayuki, T., Fujii, T., Nemoto, K. \& Daido, H. (2009). Proton-induced Nuclear Reactions Using Compact High-Contrast High-Intensity Laser. Applied Physics Express, 2, 6066001

Orimo, S., Nishiuchi, M., Daido, H., Yogo, A., Ogura, K., Sagisaka, A., Li, Z., Pirozhkov, A. S., Mori, M., Kiriyama, H., Kanazawa, S., Kondo, S., Yamamoto, Y., Shimomura, T., Tanoue, M., Nakai, Y., Akutsu, A., Nakamura, S., Shirai, T., Iwashita, Y., Noda, A., Oishi, Y., Nemoto, K., Choi, I. W., Yu, T. J., Sung, J. H., Jeong, T. M., Kim, H. T., Hong, K.-H., Noh, Y.-C., Ko, D.-K. \& Lee, J. (2007). Simultaneous Proton and X-ray Imaging with Femtosecond Intense Laser Driven Plasma Source. Jpn. J. Appl. Phys., 46, 9A, (7 September) 5853

Patel, P. K., Mackinnon, A. J., Key, M. H., Cowan, T. E., Foord, M. E., Allen, M., Price, D. F., Ruhl, H., Springer, P. T. \& Stephens, R. (2003). Isochoric Heating of Solid-Density Matter with an Ultrafast Proton Beam. Phys. Rev. Lett., 91, 12125004

Ping, Y., Shepherd, R., Lasinski, B. F., Tabak, M., Chen, H., Chung, H. K., Fournier, K. B., Hansen, S. B., Kemp, A., Liedahl, D. A., Widmann, K., Wilks, S. C., Rozmus, W. \& Sherlock, M. (2008). Absorption of short laser pulses on solid targets in the ultrarelativistic regime. Phys. Rev. Lett., 100, 8, (Feb 29) 085004, 0031-9007

Pirozhkov, A. S., Mori, M., Ogura, K., Nishimura, A., Murakami, H., Shimada, Y., Sagisaka, A., Orimo, S., Kimura, T. \& Daido, H. (2008). Transient-Grating FROG for Measurement of Sub-10-fs to Few-ps Amplified Pulses, Proceedings of Advanced Solid-State Photonics (OSA Technical Digest Series), p. MC8, Nara, Japan, 27 January 2008, Optical Society of America

Pirozhkov, A. S., Choi, I. W., Sung, J. H., Lee, S. K., Yu, T. J., Jeong, T. M., Kim, I. J., Hafz, N., Kim, C. M., Pae, K. H., Noh, Y. C., Ko, D. K., Lee, J., Robinson, A. P. L., Foster, P., Hawkes, S., Streeter, M., Spindloe, C., McKenna, P., Carroll, D. C., Wahlstrom, C. G., Zepf, M., Adams, D., Dromey, B., Markey, K., Kar, S., Li, Y. T., Xu, M. H., Nagatomo, H., Mori, M., Yogo, A., Kiriyama, H., Ogura, K., Sagisaka, A., Orimo, S., Nishiuchi, M., Sugiyama, H., Esirkepov, T. Zh., Okada, H., Kondo, S., Kanazawa, S., Nakai, Y., Akutsu, A., Motomura, T., Tanoue, M., Shimomura, T., Ikegami, M., Daito, I., Kando, M., Kameshima, T., Bolton, P., Bulanov, S. V., Daido, H. \& Neely, D. (2009a). Diagnostic of laser contrast using target reflectivity. Appl. Phys. Lett., 94, 24, (15 June) 241102-3

Pirozhkov, A. S., Kando, M., Esirkepov, T. Zh., Fukuda, Y., Chen, L.-M., Daito, I., Ogura, K., Homma, T., Hayashi, Y., Kotaki, H., Sagisaka, A., Mori, M., Koga, J. K., Kawachi, T., Kiriyama, H., Okada, H., Kawase, K., Kameshima, T., Nishimori, N., Ragozin, E. N., Faenov, A. Y., Pikuz, T. A., Kimura, T., Tajima, T., Daido, H., Kato, Y. \& Bulanov, S. V. (2009b). Demonstration of Flying Mirror with Improved Efficiency, Proceedings of 2nd Int. Symp. Laser-Driven Relativistic Plasmas Applied to Science, Industry and Medicine (AIP Conf. Proc.), pp. 274-284, Kyoto (Japan), 20 January 2009b, AIP

Pirozhkov, A. S., Mori, M., Yogo, A., Kiriyama, H., Ogura, K., Sagisaka, A., Ma, J. L., Orimo, S., Nishiuchi, M., Sugiyama, H., Esirkepov, T. Zh., Bulanov, S. V., Okada, H., Kondo, S., Kanazawa, S., Nakai, Y., Akutsu, A., Motomura, T., Tanoue, M., Shimomura, T., Ikegami, M., Shirai, T., Iwashita, Y., Noda, A., Choi, I. W., Lee, S. 
K., Lee, J., Oishi, Y., Kimura, T., Tajima, T. \& Daido, H. (2009c). Laser-driven proton acceleration and plasma diagnostics with J-KAREN laser, Proceedings of Nonlinear Optics and Applications III (Proc. SPIE), pp. 735414-10, Prague, Czech Republic, 20 April 2009c, SPIE

Racolta, P. M., Popa-Simil, L., Pascovici, G., Ivanov, E. A. \& Alexandreanu, B. (1995). In: Application of particle and laser beams in materials technology, Misaelides, P. (Ed.), 415, Kluwer Academic Publishers, 978-0-7923-3324-1, London

Robson, L., Simpson, P. T., Clarke, R. J., Ledingham, K. W. D., Lindau, F., Lundh, O., McCanny, T., Mora, P., Neely, D., Wahlstrom, C. G., Zepf, M. \& McKenna, P. (2007). Scaling of proton acceleration driven by petawatt-laser-plasma interactions. Nature Phys., 3, 1, (Jan) 58-62, 1745-2473

Roth, M., Cowan, T. E., Key, M. H., Hatchett, S. P., Brown, C., Fountain, W., Johnson, J., Pennington, D. M., Snavely, R. A., Wilks, S. C., Yasuike, K., Ruhl, H., Pegoraro, F., Bulanov, S. V., Campbell, E. M., Perry, M. D. \& Powell, H. (2001). Fast Ignition by Intense Laser-Accelerated Proton Beams. Phys. Rev. Lett., 86, 3, (Jan 15) 436

Ruhl, H., Bulanov, S. V., Cowan, T. E., Liseikina, T. V., Nickles, P., Pegoraro, F., Roth, M. \& Sandner, W. (2001). Computer simulation of the three-dimensional regime of proton acceleration in the interaction of laser radiation with a thin spherical target. Plas. Phys. Rep., 27, 5, (May) 363-371, 1063-780X

Sagisaka, A., Daido, H., Ogura, K., Orimo, S., Hayashi, Y., Nishiuchi, M., Mori, M., Matsukado, K., Fukumi, A., Li, Z., Nakamura, S., Takagaki, K., Hazama, H., Suzuki, M., Utsumi, T., Bulanov, S. V. \& Esirkepov, T. Zh. (2004). Characterization of preformed plasmas with an interferometer for ultra-short high-intensity laserplasma interactions. Appl. Phys. B, 78, 7-8, (May) 919-922, 0946-2171

Sagisaka, A., Pirozhkov, A. S., Daido, H., Fukumi, A., Li, Z., Ogura, K., Yogo, A., Oishi, Y., Nayuki, T., Fujii, T., Nemoto, K., Orimo, S., Nishiuchi, M., Hayashi, Y., Mori, M., Kado, M., Nakamura, S., Noda, A., Choi, I. W., Sung, J. H., Ko, D. K. \& Lee, J. (2006). Development of a two-color interferometer for observing wide range electron density profiles with a femtosecond time resolution. Appl. Phys. B, 84, 3, (Sep) 415-419, 0946-2171

Sagisaka, A., Daido, H., Nashima, S., Orimo, S., Ogura, K., Mori, M., Yogo, A., Ma, J., Daito, I., Pirozhkov, A. S., Bulanov, S. V., Esirkepov, T. Zh., Shimizu, K. \& Hosoda, M. (2008). Simultaneous generation of a proton beam and terahertz radiation in highintensity laser and thin-foil interaction. Appl. Phys. B, 90, 3, (March) 373-377, 09462171 (Print) 1432-0649 (Online)

Schollmeier, M., Becker, S., Geissel, M., Flippo, K. A., Blazevic, A., Gaillard, S. A., Gautier, D. C., Gruner, F., Harres, K., Kimmel, M., Nurnberg, F., Rambo, P., Schramm, U., Schreiber, J., Schutrumpf, J., Schwarz, J., Tahir, N. A., Atherton, B., Habs, D., Hegelich, B. M. \& Roth, M. (2008). Controlled Transport and Focusing of LaserAccelerated Protons with Miniature Magnetic Devices. Phys. Rev. Lett., 101, 5, (Aug 1) 055004-4

Sentoku, Y., Liseikina, T. V., Esirkepov, T. Zh., Califano, F., Naumova, N. M., Ueshima, Y., Vshivkov, V. A., Kato, Y., Mima, K., Nishihara, K., Pegoraro, F. \& Bulanov, S. V. (2000). High density collimated beams of relativistic ions produced by petawatt laser pulses in plasmas. Phys. Rev. E, 62, 57271 
Snavely, R. A., Key, M. H., Hatchett, S. P., Cowan, T. E., Roth, M., Phillips, T. W., Stoyer, M. A., Henry, E. A., Sangster, T. C., Singh, M. S., Wilks, S. C., MacKinnon, A., Offenberger, A., Pennington, D. M., Yasuike, K., Langdon, A. B., Lasinski, B. F., Johnson, J., Perry, M. D. \& Campbell, E. M. (2000). Intense High-Energy Proton Beams from Petawatt-Laser Irradiation of Solids. Phys. Rev. Lett., 85, 142945

Strickland, D. \& Mourou, G. (1985). Compression of amplified chirped optical pulses. Opt. Comm., 55 447-449

Ter-Avetisyan, S., Schnurer, M., Polster, R., Nickles, P. V. \& Sandner, W. (2008). First demonstration of collimation and monochromatisation of a laser accelerated proton burst. Laser and Particle Beams, 26, 04 637-642, 0263-0346

Toncian, T., Borghesi, M., Fuchs, J., d'Humieres, E., Antici, P., Audebert, P., Brambrink, E., Cecchetti, C. A., Pipahl, A., Romagnani, L. \& Willi, O. (2006). Ultrafast Laser-Driven Microlens to Focus and Energy-Select Mega-Electron Volt Protons. Science, 312, 5772, (April 21, 2006) 410-413

Vasváry, L., Ditrói, F., Takács, S., Szabó, Z., Szúcs, J., Kundrák, J. \& Mahunka, I. (1994). Wear measurement of the cutting edge of superhard turning tools using TLA technique. Nucl. Instr. Methods Phys. Res. Sect. B, 85, 1-4 255-259, 0168-583X

Wakita, A., Iwashita, Y., Shirai, T., Ikegami, M., Tongu, H., Souda, H., Mori, M., Yogo, A., Orimo, S. \& Nishiuchi, M. (2009). Characteristics of a laser-produced proton beam improved by a synchronous RF field. Nuclear Inst. and Methods in Physics Research, A, 599, 115-19

Yogo, A., Daido, H., Fukumi, A., Li, Z., Ogura, K., Sagisaka, A., Pirozhkov, A. S., Nakamura, S., Iwashita, Y., Shirai, T., Noda, A., Oishi, Y., Nayuki, T., Fujii, T., Nemoto, K., Choi, I. W., Sung, J. H., Ko, D. K., Lee, J., Kaneda, M. \& Itoh, A. (2007). Laser prepulse dependency of proton-energy distributions in ultraintense laser-foil interactions with an online time-of-flight technique. Phys. Plasmas, 14, 4, (Apr) 043104, 1070-664X

Yogo, A., Daido, H., Bulanov, S. V., Nemoto, K., Oishi, Y., Nayuki, T., Fujii, T., Ogura, K., Orimo, S., Sagisaka, A., Ma, J. L., Esirkepov, T. Zh., Mori, M., Nishiuchi, M., Pirozhkov, A. S., Nakamura, S., Noda, A., Nagatomo, H., Kimura, T. \& Tajima, T. (2008). Laser ion acceleration via control of the near-critical density target. Phys. Rev. E, 77, 1 Pt 2, (Jan) 016401, 1539-3755 (Print)

Yogo, A., Sato, K., Nishikino, M., Mori, M., Teshima, T., Numasaki, H., Murakami, M., Demizu, Y., Akagi, S., Nagayama, S., Ogura, K., Sagisaka, A., Orimo, S., Nishiuchi, M., Pirozhkov, A. S., Ikegami, M., Tampo, M., Sakaki, H., Suzuki, M., Daito, I., Oishi, Y., Sugiyama, H., Kiriyama, H., Okada, H., Kanazawa, S., Kondo, S., Shimomura, T., Nakai, Y., Tanoue, M., Sasao, H., Wakai, D., Bolton, P. R. \& Daido, H. (2009). Application of laser-accelerated protons to the demonstration of DNA double-strand breaks in human cancer cells. Appl. Phys. Lett., 94, 18 181502-3 


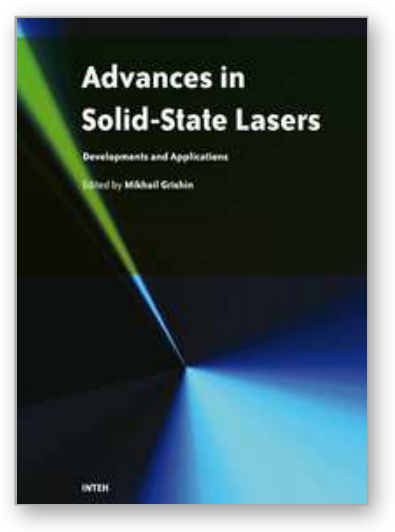

\author{
Advances in Solid State Lasers Development and Applications \\ Edited by Mikhail Grishin
}

ISBN 978-953-7619-80-0

Hard cover, 630 pages

Publisher InTech

Published online 01, February, 2010

Published in print edition February, 2010

Invention of the solid-state laser has initiated the beginning of the laser era. Performance of solid-state lasers improved amazingly during five decades. Nowadays, solid-state lasers remain one of the most rapidly developing branches of laser science and become an increasingly important tool for modern technology. This book represents a selection of chapters exhibiting various investigation directions in the field of solid-state lasers and the cutting edge of related applications. The materials are contributed by leading researchers and each chapter represents a comprehensive study reflecting advances in modern laser physics. Considered topics are intended to meet the needs of both specialists in laser system design and those who use laser techniques in fundamental science and applied research. This book is the result of efforts of experts from different countries. I would like to acknowledge the authors for their contribution to the book. I also wish to acknowledge Vedran Kordic for indispensable technical assistance in the book preparation and publishing.

\title{
How to reference
}

In order to correctly reference this scholarly work, feel free to copy and paste the following:

Alexander S. Pirozhkov, Hiroyuki Daido, Mamiko Nishiuchi and Koichi Ogura (2010). Laser-Driven Proton Acceleration Research and Development, Advances in Solid State Lasers Development and Applications, Mikhail Grishin (Ed.), ISBN: 978-953-7619-80-0, InTech, Available from:

http://www.intechopen.com/books/advances-in-solid-state-lasers-development-and-applications/laser-drivenproton-acceleration-research-and-development

\section{INTECH}

open science | open minds

\section{InTech Europe}

University Campus STeP Ri

Slavka Krautzeka 83/A

51000 Rijeka, Croatia

Phone: +385 (51) 770447

Fax: +385 (51) 686166

www.intechopen.com

\section{InTech China}

Unit 405, Office Block, Hotel Equatorial Shanghai

No.65, Yan An Road (West), Shanghai, 200040, China

中国上海市延安西路65号上海国际贵都大饭店办公楼 405 单元

Phone: +86-21-62489820

Fax: +86-21-62489821 
(C) 2010 The Author(s). Licensee IntechOpen. This chapter is distributed under the terms of the Creative Commons Attribution-NonCommercialShareAlike-3.0 License, which permits use, distribution and reproduction for non-commercial purposes, provided the original is properly cited and derivative works building on this content are distributed under the same license. 